\section{Conselhos Municipais de Saúde: atuação e representação das comunidades populares}

\author{
Municipal Health Councils: activity and \\ representation of grassroots communities
}

Silvia Gerschman 1

\title{
Introdução
}

1 Escola Nacional de Saúde Pública, Fundação Oswaldo Cruz, Rio de Janeiro, Brasil.

Correspondência S. Gerschman Departamento de Administração e Planejamento em Saúde, Escola Nacional de Saúde Pública, Fundação Oswaldo Cruz. Rua Leopoldo Bulhões 1480 , Rio de Janeiro, $R J$ 21041-210, Brasil. gerschman@ensp.fiocruz.br

\section{Abstract}

This article was based on the results of research concerning health policy in municipalities that achieved the most extensive development of decentralization and innovation in the State of Rio de Janeiro, Brazil. The study applied a questionnaire for health system users' representatives in Municipal Health Councils. The central issues were: the Councils' political role; social control by the Councils, viewed as surveillance by organized society over government actions; the nature of social representation exercised by the Council members; and the type of mandate they serve. Community representatives in the Councils reinforce aspects pertaining to the exercise of representation in unequal societies. There is a predominance of a differentiated elite consisting of older males with more schooling and higher income than the community average. The notion of "social control" as the basis for the Councils is difficult for the members to grasp. Exercise of representation is diffuse, occurring by way of designation by community associations, election in assemblies, or designation by institutional health policy agencies.

Health Policy; Health Councils (SUS); Social Control Policies
Este artigo foi desenvolvido com base nos resultados obtidos em pesquisa sobre descentralização e inovações na política de saúde nos cinco municípios que alcançaram maior desenvolvimento nesta área no Estado do Rio de Janeiro, Brasil. Uma parte da pesquisa consistiu na aplicação de um questionário aos representantes dos usuários nos Conselhos Municipais de Saúde, com o intuito de verificar a relação entre avanços na descentralização e o papel que os Conselhos Municipais de Saúde exercem na implementação da mesma. É a esta parte que o presente trabalho se dedica. Neste sentido, valemo-nos das entrevistas com 18 conselheiros municipais distribuídos em cinco municípios: Angra dos Reis, Duque de Caxias, Niterói, Resende e Volta Redonda. Cabe consignar que os conselheiros entrevistados correspondem ao total de conselheiros presentes, no momento de realização da entrevista, à reunião mensal dos Conselhos dos municípios.

É de notar-se que a composição dos Conselhos de Saúde, prevista pela Constituição de 1988, consiste em representantes do governo, prestadores de serviços públicos, privados e filantrópicos, representantes dos profissionais de saúde e das comunidades usuárias dos serviços de saúde pública. Quanto a estes últimos, a Lei 8.142 de 28 de dezembro de 1990 1, define que "a representação dos usuários nos Conse- 
lhos de Saúde e Conferências será paritaria em relação ao conjunto dos demais segmentos". Aqui lida-se exclusivamente com estes.

O trabalho inicia-se com algumas considerações teóricas e de demarcação metodológica, para, em seguida, examinar os resultados do trabalho de campo.

\section{Considerações conceituais e metodológicas}

Os estudos sobre movimentos sociais no Brasil acompanham as mudanças populacionais que se operam na passagem do Brasil rural para o Brasil urbano nos anos 50, com o crescimento desmedido das cidades principalmente do eixo Sudeste e Sul. Posteriormente, nas décadas de 70 e 80, recebem uma influência marcante da conjuntura política caracterizada pela transição do regime militar à democracia. A discussão central destes estudos, tanto os de cunho sociológico como os que se enquadram no campo da ciência política 2,3,4,5,6,7,8,9, envolvem uma multiplicidade de questões: a ação social dos movimentos; aspectos relativos à associação espontânea por contraste com a associação orgânica; sua identidade e composição social; diferenças que eles mantêm em relação a atividades de classes sociais; aspectos que os diferenciam das formas de organização sindical e das formas inorgânicas do exercício da política (a mobilização política) e, ainda, a autonomia em relação aos partidos políticos, o ressurgimento da cidadania, a relação dos movimentos com o Estado.

Todas estas perspectivas de análise dos movimentos sociais, na maioria dos estudos produzidos nas décadas de 70, 80 e parte dos 90, buscam explicar a presença na cena política de novas formas de associativismo voluntário, com modalidades inovadoras de vocalização de demandas sociais, exercidas por meio da ação política e dirigida ao reconhecimento dos direitos de cidadania social e seu exercício no controle social do processo de implementação de políticas públicas. Estes movimentos surgem nas periferias urbanas, expandem-se no processo de transição à democracia, cobrindo o país, e se caracterizam por expressar fortes conteúdos reivindicativos e de oposição ao regime militar. Assim, as liberdades políticas são o ponto de partida da mobilização social, sendo que é no próprio processo político que os direitos sociais passam a se constituir em eixo central da atua- ção destes movimentos, depositários das esperanças de um novo impulso societário dinamizador das mudanças sociais 10,11,12,13,14.

Os movimentos sociais são intrinsecamente associados às políticas sociais, já que são ligados à cidadania. Nutrem-se da experiência sindical e se originam em contextos marcados por Estados ativos na definição de políticas nacionais de desenvolvimento econômico. Governos civis e militares, na América Latina, que prometem melhorias nas condições de vida das sociedades conseguem efetivar algumas delas, mas criam ao mesmo tempo profundas desigualdades entre os que conseguem se integrar como força de trabalho nos setores industriais mais desenvolvidos e os que se encontram em condições mais precárias, com salários menores e com menor exercício da atividade sindical, geralmente inseridos na pequena e média indústria e no setor de serviços. Contudo, tanto a força de trabalho mais qualificada quanto os trabalhadores que ficam excluídos do mercado formal de trabalho e engrossam o mercado informal nos anos da ditadura militar compartilham o espaço de moradia nas favelas urbanas, nas periferias, nas cidades dormitórios.

E é neste espaço social urbano que os movimentos sociais surgem, já não associados às condições de trabalho no âmbito da empresa industrial, mas às condições de vida nas novas e precárias modalidades de habitação urbana. A coabitação promove uma nova sociabilidade, sustentada em laços de identidade em torno de condições de reprodução da vida em situação de carência, o que cria uma trama social amalgamada, em que indivíduos se identificam e se reconhecem na promoção de melhores modos de vida.

A busca de uma vida com mais saúde, educação, saneamento, moradia e a presença crescente da perda na qualidade da vida que a falta destes bens de consumo social ocasiona, formam, sob certas condições que serão tratadas adiante, como que um "caráter" por oposição, ou seja, pela via da recriação de laços sociais com base em modalidades de vida compartilhadas, antes que pela diferença da composição social dos integrantes desta nova modalidade associativa que caracteriza os movimentos sociais. Esta noção de "caráter" nos é inspirada pela notável obra de Sennet 15 .

Nas décadas de 60 a 90, estas carências tiveram um signo positivo no sentido de criar laços sociais que promoveram a ação coletiva de 
amplos setores da sociedade, pela presença e atuação dos movimentos sociais na cena política brasileira. As expectativas de mudanças, mesmo nos piores momentos da repressão política, estavam presentes pela própria existência de referências e alternativas às políticas dominantes. Como observa Guimarães 16, em relação aos processos políticos na América Latina, dos anos 60 aos 80: "no que já se entendeu por Terceiro Mundo, o desenvolvimento foi correlato funcional da social-democracia. Enquanto esta funcionava por procedimentos redistributivos, aquele contentava-se com integrar-se à modernidade industrial via elevadas taxas de crescimento, na suposição então corrente, da convergência das economias, a longo prazo, para patamares semelhantes de bem-estar".

O Brasil estava crescendo economicamente. Os partidos, ainda que proscritos, tinham propostas políticas e referências históricas, mesmo que apenas num espaço simbólico do político. Até os militares, apelando ao slogan "Brasil Grande”, em que cada brasileiro teria um lugar para conquistar, fomentavam esperança.

O regime militar se empenhou em ocultar as contradições entre opressão e liberdade, desigualdade e opulência, descaso público e o papel que cabe à esfera pública, as políticas sociais excludentes e as políticas sociais inclusivas. Em contrapartida, a própria experiência das classes subalternas - denominação genérica dos setores atingidos pelas novas e crescentes formas de exclusão no mercado de trabalho instituiu, pela mão dos movimentos sociais, a cidadania como eixo da reconstituição do tecido social.

Foi precisamente a idéia de cidadania como motor dos movimentos sociais que promoveu a formação de uma identidade entre portadores de "iguais" carências e que conduziu à inclusão dos direitos sociais nos direitos de cidadania. As políticas sociais, adquirindo o sentido de instrumento da justiça social, passaram a ser o fio transmissor entre a sociedade e um Estado omisso no período. A interdição do Estado torna-se insuficiente para controlar a ação coletiva destes novos atores, passando os movimentos sociais a se articular enquanto organismos políticos de representação da sociedade. A sua contrapartida, no exercício da política governamental já na democracia, os Conselhos Societários, se constituíram em tema central das políticas sociais e atravessaram a discussão política até o fim da década de 80 .

\section{Os movimentos sociais em saúde e as políticas de saúde}

Com base nas reivindicações de participação da sociedade na gestão das políticas sociais, foram criados, após a Constituição de 1988 e como resultado da definição constitucional relativa às mesmas, inúmeros Conselhos co-gestores de políticas públicas desde o âmbito municipal até o federal. Os Conselhos foram incorporados à Constituição, na suposição de que se tornariam canais efetivos de participação da sociedade civil e formas inovadoras de gestão pública a permitir o exercício de uma cidadania ativa, incorporando as forças vivas de uma comunidade à gestão de seus problemas e à implementação de políticas públicas destinadas a solucioná-los. A sociedade, atuando nos Conselhos, teria a possibilidade de contribuir para a definição de um plano de gestão das políticas setoriais, conferindo maior transparência às alocações e favorecendo a responsabilização dos políticos e dos técnicos da administração pública.

A definição constitucional relativa à incorporação dos Conselhos na implementação da política pública resultou da conjuntura política que o país estava atravessando: no âmago da oposição ao regime militar encontra-se importante mobilização da sociedade brasileira, participando no processo de transição à democracia. Amplas camadas da sociedade por meio de organização própria expressaram demandas, refreadas no período autoritário, por habitação, saúde, saneamento, educação, constituindo o que a literatura sociológica denominou, nos anos 70, de movimentos sociais. Estes movimentos tiveram um papel principal no processo de democratização e na formulação das políticas sociais no primeiro governo civil da transição à democracia. Marcaram, também, fortemente a Constituição nas disposições referentes à incorporação de novos órgãos de representação da sociedade, exatamente os Conselhos Societários 14.

A própria existência e a atuação desses Conselhos foi diferenciada setorialmente segundo o grau de força e expressão alcançado pelos movimentos sociais. Assim, no caso dos Conselhos de Saúde, estes resultaram da importante atuação política do movimento social em saúde desde o final da década de 70 .

Nos anos 90, pesquisa sobre a atuação do movimento popular em saúde e posterior formação dos Conselhos de Saúde no Estado do Rio de Janeiro, concluiu que os avanços conseguidos na definição da política de saúde em muito se deveram ao papel exercido pela mo- 
bilização popular e pelas lideranças do movimento. Foi pressão para que o Estado tivesse uma atuação mais incisiva quanto às condições sanitárias da população, estimando-se que o papel que o movimento conseguiu desenvolver foi definidor na implementação da Reforma Sanitária, tal como aprovada na Constituição 14.

Hoje, anos depois e no despontar do novo século, o movimento popular em saúde quase que desapareceu da cena política e os movimentos sociais em geral perderam visibilidade na sociedade e na política brasileira. Os projetos societários compartilhados com o Estado, expressos na letra Constitucional em diversos campos de política social de seguridade, saúde, educação, habitação, e que caracterizaram o início da democracia, se tornaram "confluência perversa entre um projeto participatório construído, a partir dos anos 80 , ao redor da extensão da cidadania e do aprofundamento da democracia, e o projeto de um estado mínimo que se isenta progressivamente do seu papel de garantidor de direitos sociais" 17 (p. 288). A autora citada salienta, porém, que “...apontando para direções opostas e até antagônicas, ambos os projetos requerem uma sociedade civil ativa e propositiva" 17 (p. 289).

Se bem que os Conselhos de Saúde no Brasil tenham permanecido como organismos deliberativos na implementação da política de saúde, a questão da cidadania social e da democracia participativa é apropriada no discurso e instrumentalizada na operacionalização de políticas focalizadas de atenção primaria à saúde. Por sua vez, os conselheiros representantes da sociedade nos Conselhos perderam a base política de sustentação sobre a qual tinha se forjado a identidade e a mobilização política características do movimento popular em saúde. Cabe então se perguntar: qual o papel político dos Conselhos? Que controle social exercem, entendido este como vigilância da sociedade organizada sobre as ações de governo? Qual a natureza da representação social exercida pelo conselheiro, a sua configuração dentro da esfera pública e seu tipo de mandato? Qual a efetividade do Conselho, levando em consideração sua composição, criação e funcionamento?

\section{Os Conselhos Municipais de Saúde}

\section{Perfil social dos conselheiros}

A participação dos usuários na composição dos Conselhos Municipais de Saúde configura-se, na sua grande maioria, por pessoas do sexo masculino, com idade superior a 46 anos. Desses,
$45 \%$ contam com o terceiro grau, $32 \%$ com o segundo e $23 \%$ com o primeiro grau. Estão vinculados a profissões diversas (28\% já são aposentados), sendo que $38 \%$ estão situados na faixa salarial entre quatro e oito salários mínimos e $31 \%$ percebem mais de oito salários mínimos mensais. Representam entidades das mais variadas naturezas, de sindicatos a igrejas e associações. Neste sentido, os Conselhos pesquisados são conformados por pessoas maduras, de classe média, relativamente capacitadas 18 . Dentre os entrevistados existe o caso, por exemplo, de um delegado que afirma: "fui escolhido pela Igreja e pela Associação de Moradores a que represento, apesar de não utilizar os serviços do SUS, pelo fato de estar mais preparado para defender os interesses da população, já que muitos assuntos não são do entendimento de todos".

A aptidão para compreender as questões envolvidas é especialmente valorizada pelos conselheiros e o discurso acima ilustra de modo geral como é vista a sua função. Não houve menção, no caso, ao exercício da representação política da comunidade, por intermédio das entidades que o designaram, mas antes o reconhecimento de um lugar social diferenciado na comunidade de origem. Possuidores de uma liderança meritocrática, trata-se de homens mais velhos, com formação superior e com salário bem acima dos usuários do Sistema Único de Saúde (SUS). A composição social dos conselheiros representantes dos usuários configura uma elite na comunidade a que pertencem.

\section{O papel político desempenhado pelo Conselho Municipal de Saúde}

O padrão de respostas sobre o papel político dos Conselhos é bastante disperso, revelando que o papel do Conselho não é visto de maneira consensual pelos conselheiros. A maior concentração de repostas (28\%) se localiza na função de fiscalizar e elaborar a política de saúde. O papel político - em termos dos procedimentos que acontecem no interior dos Conselhos para a aprovação de políticas originadas nos níveis federal, estadual ou nas Secretarias $\mathrm{Mu}$ nicipais - não é sequer mencionado pelos conselheiros.

Alguns representantes dos usuários acreditam que seu papel e sua atuação servem para legitimar decisões tomadas a priori pelo governo, como nos depoimentos que seguem: “o papel do Conselho é maravilhoso, mas muitas vezes os usuários são bonecos de manipulação. Para legitimar a política do governo (...) porque algumas vezes foram tomadas decisões que o Conselho não deliberou. Quando eles querem 
fazer, eles fazem”. “Não se reconhece nenhuma decisão do Conselho quando essa contraria o chefe do executivo [o prefeito e seu secretariado]".

Essas respostas, como já apontado por Labra \& Figueiredo 18 , confirmam parcialmente a idéia prevalecente na literatura sobre os Conselhos de Saúde de que é baixa a capacidade dos conselheiros usuários influenciarem nas decisões do presidente do órgão.

Ainda que a maioria considere importante a atuação do Conselho na comunidade, as respostas são bastante dispersas e pouco precisas, tanto no que se refere a motivos da importância quanto em relação à melhoria das condições de atendimento à comunidade e à própria atuação do Conselho. A idéia de "controle social" aparece nas questões analisadas com percentuais baixos. O que se observa é que ainda que se trate de um atributo fundamental dos Conselhos, idealizado pelo movimento social em saúde e incorporado à Constituição, pouco tem se avançado neste sentido.

A noção de "controle social" possui uma acepção ambígua para os conselheiros entrevistados. Ela é usada indistintamente como capacidade que a sociedade tem de interferir na gestão pública, orientando as ações do Estado e os gastos estatais na direção dos interesses da comunidade ou alternativamente como o controle que o Estado exerce sobre a sociedade.

O conceito é originário do campo das ciências sociais e refere-se à "adequação às normas ou a conferir um significado desviante à ação $e$ tem lugar na interação informal ou através de agências especialmente concebidas para este fim" 19 (p. 61). O termo é utilizado também por alguns autores para designar, especificamente, o controle que o Estado exerce sobre a sociedade por meio de suas instituições com o objetivo de reduzir, ou mesmo evitar, conflitos sociais. Essas instituições interferem no "cotidiano da vida dos indivíduos, reforçando a internalização de normas e comportamentos legitimados socialmente" (Iamamoto, 1988, apud Correia 20, p. 53). Em ambos os casos, trata-se de uma noção fortemente normativa e disciplinar relativa à vida em sociedade.

No campo da saúde e na conjuntura da transição à democracia, essa noção indicava uma nova modalidade de relacionamento da sociedade com o Estado. O controle social foi concebido como a fiscalização direta da sociedade civil nos processos de gestão da coisa pública e consistiria na apropriação, pela sociedade organizada, dos meios e instrumentos de planejamento, fiscalização e análise das ações e serviços de saúde (Bergman, 1992, apud Correia 20 ).
Os mecanismos de controle social seriam, ao mesmo tempo, resultado do processo de democratização do país e pressupostos para a consolidação dessa democracia. O fortalecimento do exercício do controle social sobre o Estado contribuiria, assim, para o alargamento da esfera pública. Neste sentido, a viabilidade do controle social seria condicionada à existência de uma democracia participativa e à institucionalização dos canais de participação em Conselhos setoriais.

Silva (1992, apud Correia 20, p. 54), sugere que o controle social desejado é a "permanente prestação de contas dos gastos públicos à sociedade e o envolvimento desta, de forma sistemática, e não apenas conjuntural, com o trato da administração de bens e serviços públicos".

Poucos entrevistados atribuem ao Conselho o papel de viabilizar o controle social. No que se refere à atuação do Conselho na comunidade, alguns respondem que "a atuação é o controle social da comunidade”. Neste caso, os entrevistados referem-se ao controle que o Conselho exerce sobre a comunidade, o que remeteria à compreensão da noção no campo das ciências sociais acima referido.

É interessante reproduzir as conclusões de Labra \& Figueiredo 18 (p. 545), relativas às manifestações dos conselheiros sobre o controle social, que se aproximam dos resultados do presente trabalho: “(...) apesar de o tema do controle social ter sido um objetivo fundamental da construção democrática do SUS, e continuar sendo tema central das conferências de saúde em todos os níveis, de incontáveis debates e de numerosas publicações, em geral não é percebido como uma realidade na prática dos CS".

De fato não se observa pelas manifestações dos conselheiros que a prática do Conselho esteja direcionada ao controle das ações do Estado, pelo contrário, mais da metade dos representantes dos usuários se refere “(...) às dificuldades existentes para que a atividade dos Conselhos influencie o processo decisório do governo local, especialmente quando as políticas existentes são contrarias às deliberações do Conselho".

Dagnino 17 (p. 282) observa que a natureza dos conflitos nos Conselhos gestores se manifesta pela "partilha do poder", na medida em que estão em jogo diferentes concepções e projetos políticos. O Executivo resiste a dirimir conflitos na arena dos Conselhos. A sociedade civil não participa efetivamente das decisões nem exerce o controle social. Cabe acrescentar que há uma modalidade autoritária de exercício da política por parte dos representantes do governo, que tendem a tutelar os representantes da sociedade civil nos Conselhos. Em todos os ca- 
sos verifica-se a despolitização dos âmbitos do exercício da cidadania/democracia participativa nas instâncias efetivas de participação societária nas políticas sociais.

Não obstante o papel do Conselho parecer um tanto vago para os entrevistados, todos afirmam participar de todas as reuniões, que para maioria deles (88\%) acontecem mensalmente. Os motivos que levam os entrevistados a participar são: "o compromisso com a população e a entidade que representam”; "o interesse nas informações recebidas"; "a oportunidade de oferecer sugestões que contribuam com as decisões”.

Conforme o depoimento de um entrevistado: "embora não tendo muita influência nas decisões do poder público, compareço às reuniões para acompanhar, entender, tentar influir nas decisões e para não ser omisso".

Tais respostas, no entanto, não permitem afirmar que o conjunto de delegados participa de $100 \%$ das reuniões. Pelo contrário, são feitas muitas queixas e ponderações por parte dos representantes dos usuários sobre a baixa participação dos demais delegados, que acabaria por comprometer o ritmo dos trabalhos iniciados. Muitos entrevistados apontaram este como o principal impedimento para uma melhor atuação do Conselho. Percebe-se que a participação é valorizada pelos representantes dos usuários nas reuniões dos Conselhos, ainda que esta não seja decisiva no andamento da política pública, os Conselhos são tidos como um espaço para o exercício da sua cidadania.

Os representantes que participam assiduamente das reuniões do Conselho, apresentam uma motivação presente no plano pessoal, qual seja o seu compromisso com a comunidade, o interesse nas informações, ou ser ouvido pelo Conselho. A função de conselheiro proporcionaria, também, um lugar de privilegio e de influência social na comunidade. O conselheiro age sob o mandato das entidades da comunidade que o escolhem para formar parte dos Conselhos, mas, na ausência de referenciais políticos expressos em projetos e/ou derivados de identidades políticas coletivas, a "participação da sociedade” na política de saúde permanece, apenas, no discurso dos Conselhos, enquanto que a disputa de interesses dos segmentos com assento nos Conselhos atualiza os poderes diferenciados que cada um destes setores - usuários, profissionais de saúde, representantes do setor privado, do setor filantrópico e governo - possui na arena setorial.

Passados pouco mais de dez anos do Estado neo-liberal, a despolitização da sociedade e a ausência da ação política baseada no envolvimento dos cidadãos é mais uma evidência do esvaziamento da democracia idealizada na transição e refletida na "Constituição Cidadã". Mas esta referência dá testemunho das perdas das comunidades populares, entre elas sua nascente identidade política forjada pela ação dos movimentos populares em saúde, na luta pela democracia e por melhores condições de vida das classes subalternas.

No início da implantação dos Conselhos, os conselheiros exerciam uma função que se originava na delegação política que a comunidade lhe outorgava. Isto não se dava sem confronto entre projetos oriundos das múltiplas organizações populares então atuantes. Agora, pela vontade do mercado e a "governabilidade" do Estado, produziu-se perda irreparável dos direitos de cidadania mais elementares, tais como o direito ao trabalho, o direito a se alimentar, o direito a morar dignamente, o direito à saúde, o direito de aceder a uma melhor formação educacional, o direito de viver sem a ameaça cotidiana da violência. Neste contexto desfavorável ao exercício da participação, a função do conselheiro sofreu importante esvaziamento político. As representações populares transformaram-se em representação dos usuários enquanto participantes mais informados e interessados nas questões referidas à saúde. No caso do Rio de Janeiro chega-se a um limite: o poder público se ausenta das comunidades populares, que passam ao controle - aí incluídas as associações de moradores - do tráfico e este dá as diretrizes que os conselheiros são obrigados a obedecer.

\section{Representação, escolha e atuação dos conselheiros}

Para Cotta 21 (p. 1106): “a representação está na verdade estreitamente ligada a um processo de duplo sentido de comunicação das mensagens políticas. É, portanto, dependente de todos os canais de informação recíproca e sensível a todas as perturbações que acontecem neste campo. A representação pressupõe, por conseguinte, um complexo de direitos políticos (...) que permitem a formação e a manifestação da vontade política dos representantes. Mais alto ainda estão certos fatores culturais. A presença junto ao público de uma cultura democrática 'participante' e não passiva e nas classes políticas de uma cultura democrática e flexível em vez de autoritária e dogmática, facilita indubitavelmente o funcionamento da representação".

Com os Conselhos, inicia-se uma prática bastante recente de representação dos usuários, moradores das comunidades populares assentadas no espaço municipal. O exercício 
dos direitos políticos é ainda bastante precário, considerando que a participação nas decisões junto ao governo municipal, na implementação da atenção à saúde, não possui registro na história nem na cultura política dessas comunidades. Pior ainda, é abortado no estágio de sua formação. Nas comunidades populares, as associações de moradores constituíram, até fim dos anos 80, o espaço político de enfrentamento e embate entre os tradicionais partidos de cunho clientelístico e os partidos de esquerda entrelaçados aos movimentos populares, desempenhando as Associações de Moradores o papel de mediadoras entre as sociedades locais e o Estado. A expectativa de que, com a democracia, o Estado se tornaria fortemente ativo no plano social foi inviabilizada com as políticas direcionadas ao ajuste econômico e à hegemonia do mercado, retirando-se o Estado da missão de implementar uma democracia com justiça social. Isto significou, de fato, a entrega do destino das comunidades populares ao avanço do tráfico de drogas: “a presença do narcotráfico em quase todas as favelas e conjuntos populares do Rio tem graves conseqüências para o poder e a autoridade legítimos, bem como para a independência política do poder local. (...) Como dispõem de poder financeiro, além de um formidável arsenal, os traficantes geralmente procuram influenciar a política da autoridade local - leia-se associações de moradores - ou mesmo eleger-se para o cargo, visando assim a 'legitimarem-se e a tornarem-se respeitáveis na comunidade”' Leeds 22 (p. 250). Na rota do tráfico, os movimentos populares e o exercício da representação política se tornam apenas uma ficção de cidadania.

A escolha dos representantes dos usuários para participar nos Conselhos Municipais de Saúde é realizada, em geral, por meio de indicações ou eleições em assembléias gerais, nas sedes das Associações de Moradores e entidades religiosas e comunitárias a serem representadas. Ainda assim, cerca de $17 \%$ desses representantes são escolhidos no âmbito das Conferências Municipais de Saúde e 5\% por meio de votação pelas diretorias das entidades a que estão vinculados. Quase a totalidade dos conselheiros consideram que: " a sua representação é legítima perante a comunidade elou a entidade que representam devido à dedicação ao Conselho Municipal de Saúde o que permitiu sucessivas reeleições".

De fato, trata-se de uma representação difusa. Na medida em que a participação política se viu profundamente afetada na última década, resultando na polarização entre a atuação institucional e a mobilização social 17, e prati- camente com a desaparição desta última, a disjuntiva entre representação e delegação institucional tem inclinado a balança em favor desta. São as comunidades que escolhem seu representante no Conselho ou são as associações, das quais os conselheiros são parte, que designam seu representante no Conselho Municipal de Saúde. De outra parte, os mecanismos utilizados para a eleição dos representantes têm baixa visibilidade, ao tempo em que a legitimidade dos conselheiros é justificada pela constatação de ter sido "eleito" sucessivas vezes para exercer o cargo.

Pode-se afirmar que o resultado para a legitimidade dos Conselhos se amplia quanto maior for o vínculo do conselheiro com sua população eleitoral e quanto mais orgânico for este vínculo. Caso contrário, toda a responsabilidade pela representação é delegada ao representante, ficando prejudicada a própria proposta de representação. Embora não sejam eleitos como representantes da maioria da população, a legitimidade dos membros do Conselho decorre de sua estreita vinculação com a sociedade, por intermédio das entidades representadas e do processo de interlocução que estas desenvolvem ou podem vir a desenvolver com a população. No caso, o canal de comunicação mais freqüentemente citado é a convocação dos conselheiros para reuniões com a comunidade, que acontecem regularmente. São utilizados também boletins e meios de comunicação próprios das entidades e associações.

Ainda que sejam mencionados tantos canais de comunicação, muitas são as queixas e ponderações relativas à baixa participação da comunidade, tais como as que se registram a seguir: "falta de interesse da população com relação à atuação dos Conselhos"; "o Conselho tem excesso de burocracia”; "(...) existem dificuldades na convivência de complementaridade entre o governo e os usuários".

Nas manifestações dos conselheiros está sempre presente a ambivalência resultante do exercício de uma representação que vem sofrendo esvaziamento político na ausência de movimentos e partidos atuantes no interior das comunidades populares. Assim, as Associações de Moradores não deixam de se fazer presentes nos Conselhos, mas a descrença da comunidade afeta o desenvolvimento da função.

Os conselheiros podem representar uma entidade ou um segmento específico da comunidade, religioso ou de outro tipo, mas o exercício da representação requer organizações políticas com capacidade de vocalização e potencialidade de gerar espaços de poder. Considerando-se que este é um espaço não preenchido 
atualmente, o interesse da comunidade nos Conselhos se dilui. O que faz com que o círculo virtuoso da representação se complete é a prestação de contas dos conselheiros e a transmissão das discussões realizadas no âmbito dos Conselhos às suas bases. Mas, dependendo da comunidade ou bairro, a própria realização das reuniões fica prejudicada na medida em que passa pelo crivo da autorização das organizações do tráfico.

Dos conselheiros consultados, 56\% expressam que o Conselho valoriza positivamente sua representação, já os restantes $44 \%$ ressaltam as dificuldades existentes no reconhecimento da atuação dos representantes, devido aos problemas existentes na relação entre os representantes dos usuários e os dos profissionais de saúde, às dificuldades que os conselheiros passam para poder participar das reuniões e ao baixo grau de comparecimento às mesmas por parte do conjunto dos conselheiros.

A representação direta dos usuários dos serviços de saúde é difícil por conta de sua dispersão e falta de articulação interna. As Associações de Moradores foram historicamente um espaço de aglutinação das comunidades populares, mas nos últimos anos sofreram um esvaziamento importante do seu papel político de representação e articulação de demandas. A ausência de organização política dos setores excluídos obviamente reforça essa dificuldade. Dá-se então, o que Oliveira 23 chama de "substituídos": setores de classe média e os quadros técnicos de suas entidades passam a ser portavozes daqueles segmentos, o que desfigura a representatividade dos Conselhos. De fato, os conselheiros que participam assiduamente das reuniões se queixam do baixo comparecimento da maioria de seus pares e dos enfrentamentos com os profissionais de saúde, que estão mais articulados e, conseqüentemente, em melhores condições de terem bom desempenho.

Alguns dos representantes dos usuários ressaltaram a importância da população se interessar pelo trabalho dos Conselhos e estar mobilizada com relação à situação do setor em nível local, conforme o depoimento que segue: "penso que não adianta simplesmente o espaço do Conselho como realidade mágica, mas sim que a sociedade participe desse espaço porque percebo que as pessoas nos procuram para saber como o conselheiro poderia ajudar numa situação ou outra. Enfim, procuram o Conselho Comunitário de Saúde para que este apresente algumas avaliações e informações dos programas e questões sobre os hospitais etc.".

Isto é relevante para se pensar que o papel dos representantes dos usuários será tanto mais importante quanto a retaguarda que a entidade que ele representa lhe oferecer em termos de advocacy e mobilização social. Na realidade, como destaca Bava 24 (p. 68), “os Conselhos não são virtuosos em si. Tornam-se virtuosos na medida em que são percebidos como espaços de decisão construídos 'pela capacidade efetiva de atuação da representação popular da coletividade".

\section{O processo decisório no Conselho \\ Municipal de Saúde}

Uma parte considerável dos conselheiros afirma que, dentre as questões da política municipal de saúde deliberada no âmbito dos Conselhos, destacam-se os benefícios aprovados (39\%); $17 \%$ afirmam que se delibera mais sobre cooperativas, convênios e organização interna; $12 \%$ indicam o orçamento na área de saúde e a prestação de contas setorial como assunto de maior deliberação; $12 \%$ a gestão de serviços, os orçamentos e as privatizações como a esfera de maior relevância.

As questões sobre as quais o Conselho delibera, ainda que centrais à orientação do SUS, fogem a uma capacitação adequada dos conselheiros. Ou seja, estes não possuem nem a força política, nem a informação, nem os conhecimentos especializados necessários para agir de maneira decisiva nas deliberações do Conselho. Para Dagnino 17 (p. 283), “(...) uma série de elementos opera na mesma direção, dificultando uma participação mais igualitária nos espaços públicos: o mais importante deles parece ser a exigência de qualificação - técnica e política - que essa participação coloca aos representantes da sociedade civil".

Os cursos de capacitação de conselheiros que estão sendo desenvolvidos em convênio entre instituições de ensino e pesquisa de vários Estados visam a resolver um destes aspectos, o da capacitação técnica. No que se refere à qualificação política, instrumento decisivo para o desenvolvimento da função de conselheiro, a conjuntura política inviabiliza o exercício da "cidadania ativa". Utilizamos este termo na acepção de Benevides 25 , que adota a expressão "cidadania ativa" numa perspectiva de soberania popular, de direitos humanos e no contexto da democratização do Estado e da sociedade. A possibilidade de participação direta no exercício do poder político confirma a soberania popular como elemento essencial da democracia e reforça a necessidade de se somarem direitos políticos aos direitos sociais. A autora recorre a Marilena Chauí para lembrar que cidadania significa conquista e criação de 
espaços sociais de lutas (movimentos sociais, sindicais e populares) e instituições permanentes para a expressão política, como partidos, legislação e órgãos do poder público. A cidadania ativa é aquela que institui o cidadão essencialmente como criador de direitos para abrir novos espaços de participação política. Segundo Bava 24 , a cidadania só pode realizar-se na ação coletiva, no espaço público, no processo de negociação em torno de interesses sociais.

Alguns representantes dos usuários acreditam que seu papel e sua atuação servem para legitimar decisões tomadas a priori pelo governo, como mostram os depoimentos que seguem: "o papel do Conselho é maravilhoso, mas muitas vezes os usuários são bonecos de manipulação"; "para legitimar a política do governo (...) porque algumas vezes foram tomadas decisões que o Conselho não deliberou"; "quando eles querem fazer, eles fazem"; "não se reconhece nenhuma decisão do Conselho quando essa contraria o chefe do Executivo [o prefeito e seu secretariado]".

O processo deliberativo correspondente a esta instância central da política de saúde que suporia que as partes envolvidas fossem igualmente informadas sobre processos, organização e financiamento do sistema de saúde; que fossem também politicamente legitimadas com forte vocalização de demandas e capacitação técnica equivalente. No caso em apreço, contudo, as Secretarias Municipais de Saúde e outras instâncias governamentais locais têm uma posição diferenciada da representação dos usuários. Acrescentam-se às dificuldades já mencionadas, os problemas derivados do exercício da representação dos conselheiros dentro das suas comunidades; acuados entre as organizações do tráfico, uma polícia contaminada e um poder público omisso, as representações dos usuários configuram reservas potenciais de uma cidadania fortemente coagida.

No que se refere à existência de impedimento para a atuação do Conselho, as respostas tiveram um padrão bastante disperso e os depoimentos dos conselheiros frisam aspectos relativos tanto à atuação dos conselheiros, quanto à do executivo: "falta disponibilidade dos conselheiros em estarem presentes compondo as comissões permanentes e provisórias, (...) sendo os conselheiros sempre vistos como adversários, num espaço de tensão"; "dentre os impedimentos existentes, destaco a questão partidária, pois muitos vêm para o Conselho não para discutir os problemas de saúde, mas sim para tratar de questões próprias"; "existem impedimentos políticos partidários do Poder Executivo e seus interesses"; "excesso de burocracia".
Para finalizar, estes depoimentos expressam a tensão entre significados atribuídos à participação das comunidades populares nos Conselhos. Cabe destacar a profunda descrença na esfera política. A “questão partidária” é vista apenas como o "tratamento de questões próprias" e a política tem a ver com os interesses particulares de quem os vocaliza: o poder executivo, as associações de moradores, as igrejas, ou quem for. Os poderes públicos são vistos como o lugar de exercício do poder que indivíduos possuem pelo fato de exercerem um cargo. Dentre esses poderes, o que fala mais alto é o "poder executivo". Isto poderia parecer uma visão simplificada dos conselheiros em relação à política. Mas não é. Como chama a atenção Hardt \& Negri 26: "o lugar da política foi desefetivado" e este "não lugar" remete a um Estado descarnado, tal como ele é. Guiado pelos interesses do mercado desempregador, provedor de insegurança social e incapaz de proteger a vida na comunidade, mas fundamentalmente disruptivo da sociabilidade, enquanto trama societária na qual é possível encontrar identificações, diferenciar-se e recriar relações cooperativas que, junto a projetos políticos, são essenciais à existência dos movimentos sociais.

\section{Conclusões}

Em poucos anos, a sociedade mudou profundamente. É impactante observar o passar do tempo na época presente. Os processos acontecem com tanta celeridade que o tempo que vai do nascimento à adolescência na vida humana pode ser a medida de profundas feridas no corpo social, de sinais e indicações aos quais os governantes deveriam estar atentos.

Os movimentos populares em saúde tiveram o selo de duas conjunturas políticas bem diferenciadas num lapso de vinte anos: a transição à democracia e a globalização econômica. A primeira marcada pela "sobredeterminação" do político, a segunda, pela "determinação" econômica.

Parece estranho voltar a utilizar a terminologia marxista para compreender a sociedade e as suas formas de expressão política. Ela se valida porque a nova sociedade recuou para o lugar e o tempo em que esta era válida. Poderia se dizer que as idéias de liberdade política, cidadania e estado de direito alimentaram os movimentos sociais e os partidos que irromperam na vida nacional, abrindo as comportas democráticas após longo interregno em que os direitos políticos e a própria política significaram a "subversão da ordem". Contudo, de maneira 
inesperada, com a nova democracia, se esvanece a "autodeterminação" da sociedade conquistada na transição, submetendo-se o Estado de Direito à perda do direito fundamental de decisão soberana de preencher uma democracia nascente com os sentidos desejados pela sociedade que operou a transição. A democracia se subordinou à “determinação" econômica do mercado financeiro internacional pela via de governos eleitos, obedientes aos desígnios dos organismos financeiros internacionais e à hegemonia americana globalizada.

As condições de exercício da cidadania da saúde somente foram dadas no processo de liberalização da sociedade e na construção de novas organizações sociais e políticas que entenderam a saúde da população com signo contrário à saúde enquanto mercado. Quatorze anos depois, os movimentos populares em saúde desapareceram da cena social e política, mas os Conselhos Municipais de Saúde permaneceram e a representação da sociedade organizada manteve assento neles e, por meio deles, lugar na implementação da política de saúde. Como permaneceram? Qual a dimensão do estrago? Os dados mostram resultados não alentadores. A representação da sociedade civil nos Conselhos foi se tornando, na conjuntura política adversa dos anos 90, mera virtualidade. Pode se observar nos Conselhos Municipais de Saúde o mesmo fenômeno apontado por outros estudos sobre Conselhos setoriais, e dentre eles destacamos o trabalho sobre o Conselho Cearense de Direitos da Mulher (Esmeraldo \& Said, 2002, apud Dagnino 17, p. 289): “sem a representação e comunicação com o movimento de mulheres, o Conselho se transforma num espaço burocrático de elaboração e execução de projetos setoriais e de legitimação de um discurso governamental que prega a participação e a cidadania".

De fato, promover uma "cidadania ativa" enquanto expressão da luta política e da mobilização da sociedade civil, sob a base de um papel efetivo dos Conselhos Gestores, faz com que o papel destas instâncias de controle social da política governamental se torne efetivamente um espaço de disputa de interesses e projetos políticos diferenciados e não apenas um espaço de representação virtual da sociedade civil.

Hoje, os representantes comunitários nos Conselhos reforçam os aspetos relativos ao exercício da representação em sociedades desiguais. O predomínio de uma elite diferenciada formada por homens, que são mais velhos, melhor educados e com salários bem maiores que a media da comunidade. Uma representa- ção que expressa e reforça as desigualdades existentes no interior das comunidades e entre os conselheiros representantes destas e os representantes governamentais, profissionais de saúde, setor privado e filantrópico.

O papel político dos conselheiros na tomada de decisões do Conselho está ausente do discurso destes. Em nenhum momento aparece mencionado pelos entrevistados. A representação é difusa, já que, de uma parte acontece, às vezes, pela designação do representante da associação de moradores ou de outro tipo de associação comunitária e, em outras ocasiões, por meio de eleições em assembléias ou por indicação de instâncias institucionais da política de saúde, tais como as Conferências Municipais de Saúde.

Ainda que a relação entre representantes e representados aconteça via reuniões, periódicos ou meios de comunicação próprios das entidades, o envolvimento das comunidades, como uma forma de interferir na gestão pública é baixo, dada a descrença sobre a contribuição que os Conselhos podem dar para a melhoria das condições de saúde da população.

O papel dos representantes no Conselho torna-se de difícil efetivação, dada a ausência de papel político e de inserção em algum tipo de militância que sustente e respalde a atuação do conselheiro. A estas carências se soma a falta de um conhecimento técnico especializado sobre o setor da saúde que permita aos conselheiros deliberar sobre assuntos apresentados pelos secretários municipais.

Finalmente, os resultados da pesquisa permitem constatar a tensão entre significados da participação das comunidades populares nos Conselhos e a noção de que a política apenas tem a ver com interesses particulares. Em definitivo, os conselheiros exercem uma função que está desprovida de um sentido político que ultrapasse interesses particulares e se inscreva no usufruto dos direitos de cidadania social das comunidades de origem. Tal como Castel 27 (p. 532) constata, a "desfiliação", enquanto ausência de pertencimento e de identidade social e política, equivale "à ausência de inscrição do sujeito em estruturas portadoras de sentido". Faltando estas, os empreendimentos sociais e a mobilização política são ilusórios e a comunidade apenas se inscreve enquanto agregado de indivíduos, incapaz de gerar projetos coletivos. 


\section{Resumo}

Este artigo foi desenvolvido com base em resultados de pesquisa sobre descentralização e inovações na política de saúde, em municípios que alcançaram maior desenvolvimento neste setor no Estado do Rio de Janeiro, Brasil. Foi aplicado um questionário aos representantes dos usuários nos Conselhos Municipais de Saúde. As questões centrais indagadas foram: o papel político dos Conselhos; o controle social exercido pelos mesmos, entendido enquanto vigilância da sociedade organizada sobre as ações de governo; a natureza da representação social exercida pelos conselheiros; assim como, o tipo de mandato. Observou-se que os representantes das comunidades nos Conselhos reforçam os aspetos relativos ao exercício da representação em sociedades desiguais. Há o predomínio de uma elite diferenciada formada por homens mais velhos, melhor educados e com salários maiores que a media da comunidade. A idéia de "controle social" como fundamento dos Conselhos é dificilmente compreendida pelos conselheiros. O exercício da representação é difuso, às vezes acontece por meio da designação do conselheiro pelas associações comunitárias e, em outras ocasiões, por eleições em assembléias ou pela designação de instâncias institucionais da política de saúde.

Política de Saúde; Conselhos de Saúde (SUS); Política de Controle Social

\section{Agradecimentos}

À Marilia Pastuk, doutoranda em Saúde Pública, que colaborou na coleta bibliográfica e organização de dados.

\section{Referências}

1. Brasil. Lei 8.142, de 28 de dezembro de 1990. Dispõe sobre a participação da comunidade na gestão do Sistema Único de Saúde - SUS e sobre as transferências intergovernamentais de recursos financeiros na área da saúde, e dá outras providências. Diário Oficial da União 1990; 31 dez.

2. Moisés JA, Allier VM, Oliveira F, Lima SS. Contradições urbanas e os movimentos sociais. São Paulo: Paz e Terra; 1977.

3. Nunes E, Jacobi P. Movimentos populares urbanos, participação e democracia. Rio de Janeiro: Associação Nacional de Pós-graduação e Pesquisa em Ciências Sociais; 1980.

4. Evers TM, Plantenberg C, Spessart S. Movimentos de bairro e Estado: luta na esfera da reprodução na América Latina. In: Moises JA, organizador. Cidade, povo e poder. São Paulo: Centro de Estudos de Cultura Contemporânea/Rio de Janeiro: Paz e Terra; 1993.

5. Durham E. Movimentos sociais: a construção da cidadania. Novos Estudos CEBRAP 1984; 2:24-31.

6. Mainwaring S, Viola E. New social movements, political culture and democracy: Brazil and Argentine in the 1980's. Telos 1984; 61:17-52.

7. Laclau E. Os novos movimentos sociais e a pluralidade do social. Rev Bras Ci Soc 1986; 1:41-7.

8. Touraine A. Palavra e sangue: política e sociedade em América Latina. Campinas: Editora Unicamp; 1989.

9. Gerschman S. Movimentos sociales en salud en busca de la reconstitución de lo social. In: Fleury S, organizador. Teoria y politica de salud en América Latina. México DF: Editora Universidad Autónoma de Xochimilco; 1992. p. 255-76.

10. Boschi RR. A arte da associação. Política de base e democracia no Brasil. São Paulo: Editora Vértice; 1987.

11. Mainwaring S. Os movimentos populares de base e a luta pela democracia. In: Stepan A, organizador. Democratizando o Brasil. Rio de Janeiro: Paz e Terra; 1988.

12. Cardoso R. Popular movement in the context of the consolidation of democracy. Notre Dame: Kellog Institute; 1989. (Working Paper 120).

13. Jacobi P. Movimentos sociais e políticas públicas. São Paulo: Cortez Editora; 1989.

14. Gerschman S. A democracia inconclusa. Um estudo da reforma sanitária brasileira. Rio de Janeiro: Editora Fiocruz; 1995.

15. Sennet RA. Corrosão do caráter: conseqüências pessoais do trabalho no novo capitalismo. Rio de Janeiro: Editora Record; 1999.

16. Guimarães C. Estado nacional, democratização e resistência. In: Lessa C, organizador. Pensando o Brasil II. Rio de Janeiro: Editora Razão Cultural; no prelo.

17. Dagnino E. Sociedade civil e espaços públicos no Brasil. Rio de Janeiro: Paz e Terra; 2002.

18. Labra E, Figueiredo J. Associativismo, participação e cultura cívica: o potencial dos Conselhos de Saúde. Ciênc Saúde Coletiva 2002; 7:537-47.

19. Lemert EM. Human deviance, social problems and social control. 2nd Ed. Englewood Cliffs: Prentice Hall; 1972. 
20. Correia MVC. Que controle social? Os conselhos de saúde como instrumento. Rio de Janeiro: Editora Fiocruz; 2000.

21. Cotta M. Representação política. In: Bobbio N, Matteucci N, Pasquino G, organizadores. Dicionário de política. 9a Ed. Brasília DF: Editora UnB; 1997.

22. Leeds E. Cocaína e poderes paralelos na periferia urbana brasileira. In: Zaluar AA, organizador. Um século de favela. Rio de Janeiro: Editora FGV; 1999.

23. Oliveira F. A questão do Estado. São Paulo: Associação Brasileira de Organizações Não Governamentais; 1995. (Cadernos ABONG no 8).

24. Caccia BS. Os Conselhos como instrumentos da sociedade. In: Carvalho MC, Teixeira AC, organi- zadores. Conselhos gestores de políticas públicas. Revista Polis 37. São Paulo: Instituto de Estudos, Formação e Assessoria em Políticas Sociais; 2000.

25. Benevides MVM. A cidadania ativa: referendo, plebiscito e iniciativa popular. São Paulo: Editora Ática; 1991.

26. Hardt M, Negri A. Império. 3a Ed. Rio de Janeiro: Editora Record; 2001.

27. Castel R. As metamorfoses da questão social: uma crônica do salário. 3a Ed. Petrópolis: Editora Vozes; 2001.

Recebido em 05/Mai/2003

Versão final reapresentada em 23/Jan/2004

Aprovado em 16/Jul/2004 